\title{
BMJ Open Cross-cultural adaptation and psychometric validation of the Persian version of the Cardiac Rehabilitation Barriers Scale (CRBS-P)
}

\author{
Mahdieh Ghanbari-Firoozabadi, ${ }^{1}$ Masoud Mirzaei, ${ }^{1}$ Mohammadreza Vafaii Nasab, ${ }^{1}$ \\ Sherry L Grace (1) , ${ }^{2,3}$ Hassan Okati-Aliabad, ${ }^{4}$ Farzan Madadizadeh (D) , \\ Hakimeh Dadras, ${ }^{1}$ Najmeh Amrolahi, ${ }^{1}$ Mohamadmehdi Entezari, ${ }^{1}$ \\ Seyed Mahmood Sadrbafghi ${ }^{1}$
}

To cite: Ghanbari-

Firoozabadi M, Mirzaei M, Vafaii Nasab M, et al. Crosscultural adaptation and psychometric validation of the Persian version of the Cardiac Rehabilitation Barriers Scale (CRBS-P). BMJ Open 2020;10:e034552. doi:10.1136/ bmjopen-2019-034552

- Prepublication history and additional material for this paper are available online. To view these files, please visit the journal online (http://dx.doi org/10.1136/bmjopen-2019034552).

Received 08 November 2019 Revised 07 February 2020 Accepted 02 April 2020

Check for updates

(C) Author(s) (or their employer(s)) 2020. Re-use permitted under CC BY-NC. No commercial re-use. See rights and permissions. Published by BMJ.

For numbered affiliations see end of article.

Correspondence to Dr Farzan Madadizadeh; f.madadizadeh@ssu.ac.ir

\section{ABSTRACT}

Objectives This study aimed to translate, cross-culturally adapt and psychometrically validate a Persian version of the Cardiac Rehabilitation Barriers Scale (CRBS-P) and to identify the main barriers in an Iranian setting.

Setting Afshar cardiac rehabilitation (CR) centre, affiliated with the Yazd University of Medical Sciences, in the centre of Iran.

Design This was a multimethod study, culminating in a cross-sectional survey.

Participants Inpatient CR graduates who did not attend their initial outpatient CR appointment.

Method The 21-item CRBS was translated and crossculturally adapted in accordance with best practices; an expert panel considered the items and previous nonattending patients were interviewed via phone to refine the scale. Next, structural validity was assessed; participants were invited to complete the CRBS on the phone between March 2017 and February 2018. Using exploratory factor analysis (EFA) with principal component analysis extraction and oblique rotation. Second, confirmatory factor analysis (CFA) was used to verify the results; several goodness-offit indices were considered. The internal consistency and 3 -week test-retest reliability of the scale ( $5 \%$ subsample) were evaluated using Cronbach's $\alpha$ and intraclass correlation (ICC), respectively.

Results Face, content and cross-cultural validity were established by the experts and patients $(n=50)$. One thousand and one hundred $(40.7 \%)$ of the 2700 patients completed the CRBS-P. Structural validity was established by EFA (Bartlett's test $p<0.001 ;=0.759$ ) and confirmed by the CFA; a four-factor solution with 18 items accounting for $61.256 \%$ of variance had the best fit $\left(\chi^{2} / \mathrm{df}=3.206\right.$, root mean square error of approximation $=0.061$ and Comparative Fit Index=0.959). The internal consistency and test-retest reliability $(n=42)$ of the scale were acceptable (ICC $=0.74395 \% \mathrm{Cl}$ (0.502 to 0.868); overall $\alpha=0.797$ ). The top barriers were not knowing about $C R$, cost and lack of encouragement from physicians. Conclusion The four-factor, 18-item CRBS-P had good psychometric properties, and hence can be reliably and validly used to measure CR barriers in Iran and other Persian-speaking populations.
Strengths and limitations of this study

- Little is known about cardiac rehabilitation barriers in low-resource settings, including Iran; this study assessed them in over 1000 Iranian patients.

- A new statistical validation method, namely, the three-faced construct validation method, was used to validate a translated tool that can now be used to reliably assess barriers in Persian-speaking cardiac patients

- Generalisability is limited, and there may be selection bias due to the fairly low response rate.

\section{INTRODUCTION}

Cardiovascular diseases (CVD) are among the leading burdens of disease and cause of disability globally, ${ }^{1}$ including Iran. ${ }^{2}$ Secondary prevention through cardiac rehabilitation (CR) programmes is highly recommended in international clinical practice guidelines for these patients. ${ }^{3}$ This is because CR participation is associated with approximately $20 \%$ lower cardiovascular mortality and rehospitalisation ${ }^{4}$ and significantly improves quality of life, ${ }^{5}$ all in a cost-effective manner. ${ }^{6}$ Data from Iran corroborate the benefits of $\mathrm{CR}^{7-10}$

Unfortunately, CR is underused, particularly when compared with other secondary prevention recommendations for CVD. ${ }^{11}$ Studies conducted in Iran also demonstrate gross under-referral, enrolment, adherence and completion. ${ }^{12}$ A study by Sarrafzadegan et al in Isfahan suggested that CR attendance rate was $3.8 \%$ among all revascularisation patients ${ }^{13}{ }^{14}$; another study by Moradi et al in Tehran showed that this rate was $87 \%$ among the referred patients, ${ }^{15}$ suggesting the low use is partially due to lack of referral. According to the data from our centre, $6.9 \%$ of patients 
with a CR indicated-condition participate in CR and $43 \%$ of them do not complete the programme. ${ }^{16}$

Reasons for CR under use are well known and involve factors at the health system, referring provider, programme and patient levels. ${ }^{17}$ There have only been 13 studies of CR barriers in low-resource settings, ${ }^{18}$ with only a few in Iran. ${ }^{15} 19$ However, there has been great recent interest in developing valid tools to assess the barriers to mitigate them. The CR adherence tool, while valid, does not consider factors that may impede initial enrolment. ${ }^{20}$ The Cardiac Rehabilitation Barriers Scale (CRBS) is arguably the most widely administered, ${ }^{21-27}$ comprehensive and psychometrically validated tool to assess patient barriers to CR enrolment and participation from the patient to health system levels. ${ }^{28}$ It was developed following a review of the literature and revised with input from healthcare providers including CR staff. To date, it has been translated to 14 languages (http://sgrace.info.yorku.ca/ cr-barriers-scale/crbs-instructions-and-languages-translations/). The purpose of this study was to translate, crossculturally adapt and psychometrically validate a Persian version of the CRBS (CRBS-P). Second, the objective was to identify the main CR barriers in an Iranian setting.

\section{METHODOLOGY \\ Design}

To translate, cross-culturally adapt and psychometrically validate the CRBS-P, a series of steps were performed, as outlined below. The translation and cross-cultural adaptation of the scale were carried out on the basis of best practice recommendations. ${ }^{29-32}$ Elements of the psychometric validation conform with the Consensus-based Standards for the Selection of Health Measurement Instruments (COSMIN) taxonomy. ${ }^{33}$

\section{Research instrument}

The 21-item CRBS assesses perceived CR barriers from cardiac patients' perspectives. ${ }^{28}$ This scale assesses barriers affecting both patient enrolment and participation, at the levels of patient, healthcare providers and healthcare system in patients with any CR indication. Items are rated on a 5-point Likert-type scale that ranged from $1=$ strongly disagree to $5=$ strongly agree. Higher mean scores indicate greater barriers to patient enrolment and participation (not relevant to this study) in CR. The original English 21-item version of the scale comprises four subscales, namely, healthcare system issues, logistical factors, work/ time conflicts and comorbidities/functional status. ${ }^{28}$

\section{CRBS translation and cross-cultural adaptation process}

To oversee the translation and cross-cultural validation of the questionnaire, a team of four experts comprising a cardiologist, a health educator, a CR specialist and an English language $\mathrm{PhD}$, proficient in both Persian and English, was formed.

The questionnaire was independently translated to Persian by two native persons familiar with CR (forward step), and the two translations were assessed for grammar and wording by the team. Differences in meanings and structures of sentences and phrases were explored, and the translations were harmonised. The Persian forward translation was translated back into English again by two English specialists (backward step), and these two back translations were then harmonised.

This English version of the scale was sent to the original author of the English CRBS (SLG) for consideration. On her final approval, legibility, meaningfulness and usability of the scale items were then assessed through qualitative interviews.

\section{Participants}

Patients with the CR indications of myocardial infarction, coronary artery disease, chronic angina pectoris and heart failure and/or who had coronary revascularisation, that had undergone inpatient CR in Afshar CR centre, Yazd, central Iran, and had not presented to the outpatient CR centre at their appointed time between March 2017 and February 2018 comprised the population. The inclusion criterion was cardiac patients without any other condition that would preclude them from participating in CR. There were no exclusion criteria.

\section{Patient and public involvement}

Patients and/or the public were involved in the design, or conduct, or reporting, or dissemination plans of this research.

Previous inpatient CR participants who did not attend CR were telephoned to request their input. This was a convenience sample, but attempts were made to purposively call those of varying ages, sex and literacy levels. The items were discussed with consenting patients; the meaning of the items was discussed, the relationships between the items and how the patients perceived the items. Coauthor HO-A interviewed participants and did the initial analysis. The content and cross-cultural validity were established through these qualitative interviews with participants which were audio-recorded; interviews continued until no new comments arose. Recordings were coded to identify specific potential revisions to items.

Finally, an in-person group discussion of the expert panel was held, to finalise revisions to the scale items based on the results of interviews until consensus was achieved.

\section{Psychometric validation}

For the psychometric validation (factor structure, reliability), participants were administered the CRBS-P on the phone, on obtaining verbal informed consent (written consent was not possible given high illiteracy rate).

A random subsample of $5 \%$ of the participants $(n=55)$ was telephoned to readminister the scale 3 weeks after the first completion; the random subsample was generated via MS Excel. A 3-week interval was chosen as per the literature. ${ }^{34}$ 
Tests of psychometric properties and statistical analyses

The face validity, content validity and cross-cultural validity of the Persian translation were considered by the expert team and patient interviewees. All inputs received were considered by the investigators and applied/integrated as applicable.

To establish the structural validity of the scale, exploratory factor analysis (EFA) was first performed and then the results were verified by confirmatory factor analysis (CFA). The 3-faced construct validation method was used $^{30}$; the sample was randomly split into three parts: $20 \%$ for EFA ( $\mathrm{n}=220), 40 \%$ for CFA and $40 \%$ for a crossvalidating CFA ( $\mathrm{n}=440$ for both). During EFA, the factors were extracted with principal component analysis (PCA) using oblique rotations (direct oblimin) on the basis of correlations among the factors. The results of Bartlett's sphericity test (significant tests demonstrate adequacy) and Kaiser-Mayer-Olkin (KMO) measure of sampling adequacy ( $\geq 0.6$ is considered good) were used to ascertain the adequacy of the EFA. To determine the factor structure based on the PCA, the scree plot was examined, and factors with Eigenvalues $>1$ were extracted. To interpret latent factors, factor loadings $\geq 0.3$ were interpreted. If an item loaded on multiple factors, the factor with the greatest factor loadings was considered as the owner of that item.

To compare the performance of various CFA models, $\chi^{2} / \mathrm{df}$, the Incremental Fit Index (IFI), Tucker-Lewis Index (TLI), Comparative Fit Index (CFI), root mean square error of approximation (RMSEA), Akaike information criterion (AIC) and Bayesian information criterion (BIC) were used; values less than 4 were considered indicative of good model fit for $\chi^{2} / \mathrm{df}$, values $>0.9$ for CFI, IFI and TLI and values $\leq 0.06$ for RMSEA. ${ }^{35}$ To determine the best-fitting model, the one with the lowest BIC and AIC was selected.

Three-week test-retest reliability of the CRBS-P was assessed using intraclass correlation coefficient (ICC), which calculated from two-way mixed statistical model and absolute agreement type of ICC selected. ICC can range from 0 to 1 , and a value $>0.7$ indicates good reliability. Internal consistency was assessed via Cronbach's $\alpha$ $(\alpha \geq 0.7 \text { is acceptable })^{36}$ The data were analysed with SPSS V.24 (IBM) and AMOS V.24.

\section{RESULTS}

\section{Translation and cross-cultural adaptation}

The face validity of the scale was established through the expert panel opinion and content validity through the qualitative interviews with 50 participants. Both groups also confirmed the cross-cultural validity of the CRBS-P. During the process, all the items were clarified and simplified as much as possible. All patients were satisfied with the number and comprehensibility of the items. There was no need for great changes in item content through translation and cross-cultural adaptation of the scale. The participants completed the scale in maximally $5 \mathrm{~min}$.
Table 1 Characteristics of participants included in test of structural validity, $n=1100$

\begin{tabular}{|c|c|c|}
\hline Characteristic & \multicolumn{2}{|l|}{ Descriptive statistics } \\
\hline Age (years) & \multicolumn{2}{|l|}{ Mean $=63.13, \mathrm{SD}=13.15$} \\
\hline \multirow[t]{3}{*}{ Work status } & Unemployed/retired & $315(28.6 \%)$ \\
\hline & Employee & $423(38.5 \%)$ \\
\hline & Housewife & 362 (32.9\%) \\
\hline \multirow[t]{2}{*}{ Sex } & Male & $730(66.4 \%)$ \\
\hline & Female & 370 (33.6\%) \\
\hline \multirow[t]{4}{*}{ Education level } & Illiterate & $604(54.91 \%)$ \\
\hline & $\leq$ High school & $398(36.18 \%)$ \\
\hline & $\begin{array}{l}\text { Associate's or } \\
\text { bachelor's degree }\end{array}$ & $82(7.46 \%)$ \\
\hline & $\begin{array}{l}\text { Master's degree or } \\
\text { above }\end{array}$ & $16(1.45 \%)$ \\
\hline \multirow[t]{2}{*}{ Marital status } & $\begin{array}{l}\text { Single, divorced or } \\
\text { widowed }\end{array}$ & $11(1.0 \%)$ \\
\hline & Married & 1089 (99.0\%) \\
\hline Number of children & Mean=4.71, SD=2.29 & \\
\hline
\end{tabular}

\section{Respondent characteristics}

One thousand and one hundred (40.7\%) of the 2700 cardiac patients who qualified to present to Afshar Outpatient CR centre, Yazd, Iran but did not attend during the period of the study and completed the phone survey comprised the sample. Table 1 displays the sociodemographic characteristics of these participants.

\section{Psychometric validation}

Structural validity was investigated via EFA. The KMO value was 0.759 , and the results of Bartlett's test were significant $(p<0.001)$. On the basis of scree plot (figure 1$)$ and the EFA, there were four factors extracted with eigenvalues $>1$ that accounted for $61.26 \%$ of the total variance; hence,

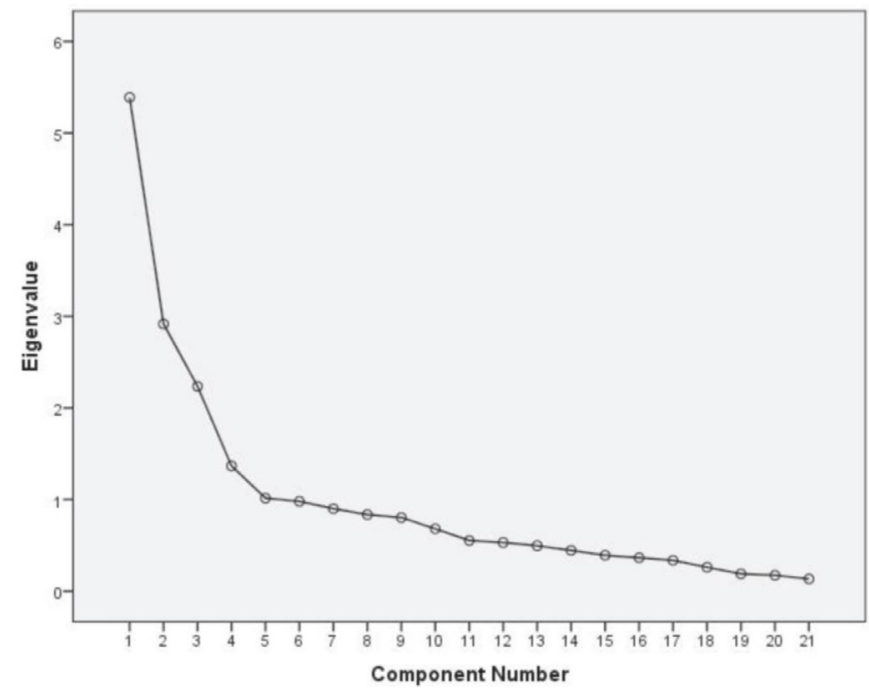

Figure 1 Scree plot from exploratory factor analysis. 
Table 2 Exploratory factor analysis $(n=20 \%$ of data $=220)$

\begin{tabular}{|c|c|c|c|c|c|c|}
\hline \multirow[b]{2}{*}{$\begin{array}{l}\text { Subscales } \\
\text { CRBS item }\end{array}$} & \multicolumn{4}{|l|}{ Factor loadings } & \multirow[t]{2}{*}{ Mean } & \multirow[t]{2}{*}{ SD } \\
\hline & $\begin{array}{l}\text { Perceived } \\
\text { need/healthcare } \\
\text { factors }\end{array}$ & $\begin{array}{l}\text { Logistical } \\
\text { factors }\end{array}$ & $\begin{array}{l}\text { Comorbidities/functional } \\
\text { status }\end{array}$ & $\begin{array}{l}\text { Work/time } \\
\text { conflicts }\end{array}$ & & \\
\hline $\begin{array}{l}21) \ldots \text { I prefer to take care of my } \\
\text { health alone, not in a group }\end{array}$ & 0.893 & & & & 2.48 & 0.609 \\
\hline $\begin{array}{l}18) \ldots \text { I can manage my heart } \\
\text { problem on my own }\end{array}$ & 0.866 & & & & 2.55 & 0.686 \\
\hline $\begin{array}{l}20) \ldots \text { it took too long to start the } \\
\text { outpatient program after referral }\end{array}$ & 0.847 & & & & 2.53 & 0.549 \\
\hline $\begin{array}{l}\text { 17)... many people with heart } \\
\text { problems don't go, and they are fine }\end{array}$ & 0.795 & & & & 2.44 & 0.639 \\
\hline 01$) \ldots$ of distance & & 0.849 & & & 2.5 & 1.252 \\
\hline 02)... of cost & & 0.8 & & & 2.59 & 1.233 \\
\hline 04)... of family responsibilities & & 0.579 & & & 2.22 & 0.962 \\
\hline 13)... I don't have the energy & & & 0.916 & & 2.27 & 1.058 \\
\hline 15)... I am too old & & & 0.868 & & 2.29 & 1.078 \\
\hline 09)... I find exercise tiring or painful & & & 0.862 & & 2.27 & 0.964 \\
\hline $\begin{array}{l}\text { 14)... other health problems prevent } \\
\text { me from going }\end{array}$ & & & 0.779 & & 2.52 & 1.203 \\
\hline 10)... travel & & & & 0.66 & 2.05 & 0.825 \\
\hline 05)... I didn't know about CR & & & & 0.351 & 3.35 & 1.31 \\
\hline Eigenvalues & 4.669 & 3.417 & 2.771 & 2.006 & & \\
\hline Variance explained (\%) & 22.232 & 16.273 & 13.197 & 9.554 & & \\
\hline Cumulative variance explained (\%) & 22.232 & 38.505 & 51.702 & 61.256 & & \\
\hline Reliability: Cronbach's $\alpha^{*}$ & 0.877 & 0.82 & 0.884 & 0.668 & Overal & 0.797 \\
\hline
\end{tabular}

*Based on 18-item version.

the scale items were categorised into four subscales. The Eigenvalues, EFA results and the variance explained by each factor are displayed in table 2. As shown, the four factors, namely, 'perceived need/healthcare factors', 'logistical factors', 'comorbidities/functional status' and 'work/time conflicts', were consistent with the original English version.

CFA was carried out to confirm the structure suggested by the EFA. The results showed that four factors with 18 items had the best fit with the study data. Items 5, 6 and 8 were omitted from the scale (ie, 'I didn't know about CR; I don't need CR; severe weather'). The CFA path diagram of the recommended model for the CRBS-P plotted with standardised parameter estimates is displayed in figure 2.

Cronbach's $\alpha$ for each factor and for the whole scale, given in table 2, demonstrates its more than satisfactory internal consistency. The 3-week test-retest reliability of the CRBS-P in $42(76.4 \%)$ responding patients was also acceptable (ICC $=0.74395 \%$ CI 0.502 to 0.868 ).

The final 18-item CRBS-P is shown in online supplementary appendix 1 (also available online at http:// sgrace.info.yorku.ca/cr-barriers-scale/crbs-instructions-and-languages-translations/). Table 2 presents mean item scores; 'not knowing about CR' was the 


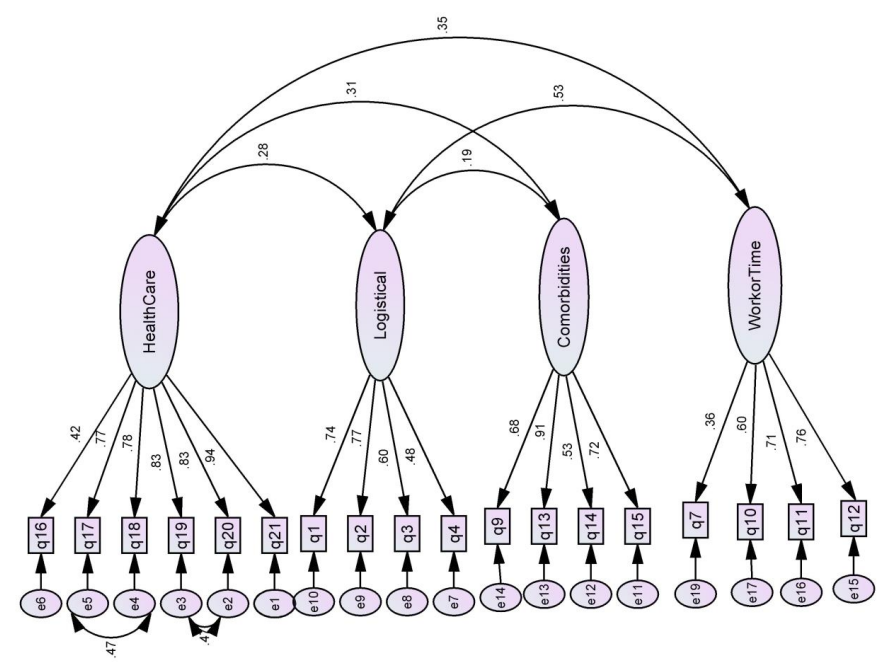

Figure 2 Path diagram for confirmatory factor analysis, displaying the four-factor model, with standardised parameter estimates. Deleted items: 5, 6 and 8 (total items=18/21).

greatest barrier (item 5), followed by cost; severe weather and time constraints hindered enrolment least. Given item 5 was the most highly endorsed item, contrary to the CFA, future researchers should consider including it in the administered scale.

\section{DISCUSSION}

Herein, an 18-item CRBS-P was demonstrated to be reliable, internally consistent and to have acceptable face, content, cross-cultural and structural validity. The top barriers identified included not knowing about CR, cost, comorbidities, perceptions of sufficient independent exercise and capacity to self-manage their CVD (reflecting lack of knowledge of what CR entails and potentially denial), lack of perceived encouragement by referring providers, wait times, transportation and distance.

We discovered that another group was simultaneously translating and validating a CRBS-P. ${ }^{37}$ Similarly, they used best practices in translation, although the credentials of those who undertook the translation are not clear. Three different items were removed, and four items were added. Inclusion of each item was rated by experts quantitatively. Test-retest reliability was also established, after 2 weeks versus the 3 weeks applied herein. Structural validity was not tested, but criterion validity was, and shown to be evident in that attendees and non-attendees had statistically significantly different barrier scores on items. The top barriers, namely, cost, transport and distance were somewhat comparable to the findings herein. It would be ideal to harmonise the two versions through further psychometric validation.

The CRBS was originally developed in English in Canada $^{28}$ and has been psychometrically validated in Brazilian, ${ }^{38}$ Korean, ${ }^{39}$ Spanish $^{40}$ and Malay ${ }^{41}$ languages (other non-validated translations are available on CRBS website). The results of the present study, similar to the original English version as well as the Korean, Malay and Spanish versions, identified four factors (table 3). On the contrary, the Brazilian version by Ghisi et al identified five factors, namely: comorbidities/functional status, perceived need/healthcare system factors, personal/ family issues, travel/conflicts with work schedule and access, ${ }^{38}$ and the Korean version by Baek et al identified six factors, namely: comorbidities/functional limitations, perceived need, external factors (similar to work/time conflicts), logistical factors, healthcare system factors and already exercising. ${ }^{39}$ The Persian CRBS, similar to the Malay version by Chai $e t$ al and the Colombian version by Sánchez Delgado et al, comprised four factors, although the items loading on each factor did differ somewhat for each when compared with the English version. ${ }^{40}{ }^{41}$ This suggests that different barriers may be at play in different contexts. It may be worthwhile to consider all the CRBS translations now available and forward a more internationally relevant revised version for further validation.

The top barriers identified point to some strategies which could potentially increase utilisation. Evidencebased strategies to increase referral ${ }^{42}$ as well as enrolment and participation have been established. ${ }^{43}$ Ensuring that inpatients are informed about CR prior to discharge is clearly a key factor, including information on what it entails and the benefits, and providing strong, positive CR endorsement. ${ }^{11}$ Increasing the number of Iranians with insurance coverage would also facilitate use, given the policy there for such reimbursement. ${ }^{44}$ Transportation and distance barriers can be overcome with alternative

\begin{tabular}{lllllllr}
\hline \multicolumn{2}{l}{ Table 3 Goodness of fit indices for factor structure of CRBS translations } & & & & & \\
\hline Factor structure (translation) & $\chi^{2} / \mathbf{d f}$ & RMSEA $(\mathbf{9 0} \%$ Cl) & TLI & CFI & IFI & AIC & BIC \\
\hline Four oblique factors* (our study) & 3.206 & $0.061(0.052$ to 0.069$)$ & 0.946 & 0.959 & 0.959 & 337.648 & 509.128 \\
Five oblique factors (Brazilian-Portuguese) & 3.965 & $0.070(.065$ to 0.076$)$ & 0.875 & 0.894 & 0.895 & 809.738 & 1047.172 \\
Six oblique factors (Korean) & 5.593 & $0.094(0.087$ to 0.102$)$ & 0.874 & 0.9 & 0.9 & 613.302 & 787.472 \\
Four oblique factors (Malay) & 7.18 & $0.119(0.113$ to 0.125$)$ & 0.674 & 0.716 & 0.718 & 1410.706 & 1606.871 \\
Four oblique factors (Spanish) & 4.87 & $0.094(0.88$ to 0.99$)$ & 0.796 & 0.822 & 0.823 & 988.586 & 1184.751
\end{tabular}

*This model included specified covariance between error terms such as 4 and 5, 5 and 2 and 3 . Item numbers 5, 6 and 8 were deleted. AIC, Akaike information criterion; BIC, Bayesian information criterion; CFI, Comparative Fit Index; CRBS, Cardiac Rehabilitation Barriers Scale; df, degree of freedom; IFI, Incremental Fit Index; RMSEA, root mean square error of approximation; TLI, Tucker-Lewis Index. 
CR delivery models, which are also shown to be effective in Iran. ${ }^{45-47}$

Directions for future research include establishing other psychometric properties of the scale, as per the COSMIN taxonomy, ${ }^{33}$ such as criterion validity through comparison of CRBS scores in enrollees and non-enrollees and/or completers and non-completers. ${ }^{28}$ It is assumed that criterion validity will be upheld in the CRBS-P, as it has been established in other translations, ${ }^{28}$ including the other Persian translation. ${ }^{37}$ Discriminant validity has also been established in the English CRBS in terms of sex, age and socioeconomic differences, ${ }^{23}{ }^{25}{ }^{26}$ but further exploration in an Iranian sample, including consideration of literacy would be useful. Exploration of interpretability of scores would also be important, but consideration of mean scores in enrollees and non-enrollees should be considered, as they are significantly higher in enrollees (as per criterion validity above), and it does appear that scores are higher in lower resource when compared with higher resource settings. Moreover, responsiveness should be investigated; mitigation strategies specific to barriers/subscales could be implemented, and the scale readministered to establish this. Finally, differential item functioning should be explored to examine possible cultural differences.

\section{Limitations}

Caution is warranted in interpreting these results. First, the translations were undertaken by bilingual clinician-researchers, but certified translators were not enlisted. Second, generalisability is limited in that participants were recruited from a single, public centre. Generalisability to patients hospitalised in private centres, where many cardiac patients receive care in Iran, remains to be established. Third, participants may have responded in a socially desirable manner as the survey was administered on the phone for logistical reasons (high illiteracy; to reach desired population of patients who do not enroll in CR). The findings from the other CRBS-P do support generalisability and that there was no response bias due to the method of administration, however there were some differences in some of the top barriers. ${ }^{37}$ Fourth, we did not systematically document the characteristics of the patients called to provide input on the translation in terms of face, content and cross-cultural validity; therefore it is unknown whether they are representative of the average cardiac patient indicated for CR. Finally, there may be selection bias due to the fairly low response rate for the validation sample.

\section{CONCLUSION}

The 18-item, four-factor Persian translation of the CRBS is highly reliable (internally consistent, test-retest), with demonstrated content (including face) and construct (including cross-cultural and structural) validity. Further exploration of CR barriers in the Iranian context can now be explored, and mitigation strategies applied to increase CR utilisation in the country, and hence curtail the burden of CVD.

\section{Author affiliations}

${ }^{1}$ Yazd Cardiovascular Research Center, Shahid Sadoughi University of Medical

Sciences, Yazd, Iran

${ }^{2}$ Faculty of Health, York University, Toronto, Ontario, Canada

${ }^{3}$ KITE-Toronto Rehabilitation Institute, University Health Network, Toronto, Ontario,

Canada

${ }^{4}$ Health Promotion Research Center, Zahedan University of Medical Sciences,

Zahedan, Iran

${ }^{5}$ Research Center of Prevention and Epidemiology of Non-Communicable Disease, Departments of Biostatistics and Epidemiology, School of Public Health, Shahid

Sadoughi University of Medical Sciences, Yazd, Iran

Acknowledgements The authors would like to thank all the patients and experts for participating in this study. We are grateful to Dr Taslima Mamataz for her support in formatting the manuscript and referencing.

Contributors MG-F designed the study, acquired data and wrote the first draft of the paper. SLG, MG-F, ME, SMS, NA and MVN contributed to translation and finalisation of the measure. MM, MVN, HO-A, HD, NA, ME, SMS and FM contributed to data acquisition and drafting the manuscript. FM and MM analysed the data. SLG interpreted the findings and revised the manuscript for important intellectual content. All authors read and approved the final manuscript.

Funding The authors have not declared a specific grant for this research from any funding agency in the public, commercial or not-for-profit sectors.

Competing interests None declared.

Patient consent for publication Obtained.

Ethics approval Before beginning the data collection process, approval from the Ethics Committee of Medical Sciences of Shahid Sadoughi University, Yazd, Iran (no. IR.SSU.MEDECINE.REC.1396.51) was obtained.

Provenance and peer review Not commissioned; externally peer reviewed.

Data availability statement Data are available upon reasonable request. The data set for this study is available on reasonable request from the Corresponding author.

Open access This is an open access article distributed in accordance with the Creative Commons Attribution Non Commercial (CC BY-NC 4.0) license, which permits others to distribute, remix, adapt, build upon this work non-commercially, and license their derivative works on different terms, provided the original work is properly cited, appropriate credit is given, any changes made indicated, and the use is non-commercial. See: http://creativecommons.org/licenses/by-nc/4.0/.

\section{ORCID iDs}

Sherry L Grace http://orcid.org/0000-0001-7063-3610

Farzan Madadizadeh http://orcid.org/0000-0002-5757-182X

\section{REFERENCES}

1 Thomas H, Diamond J, Vieco A, et al. Global atlas of cardiovascular disease 2000-2016: the path to prevention and control. Glob Heart 2018;13:143-63.

2 Forouzanfar MH, Sepanlou SG, Shahraz S, et al. Evaluating causes of death and morbidity in Iran, global burden of diseases, injuries, and risk factors study 2010. Arch Iran Med 2014;17:304-20.

3 Smith SC, Benjamin EJ, Bonow RO, et al. AHA/ACCF secondary prevention and risk reduction therapy for patients with coronary and other atherosclerotic vascular disease: 2011 update: a guideline from the American heart association and American College of cardiology Foundation. Circulation 2011;124:2458-73.

4 Kabboul NN, Tomlinson G, Francis TA, et al. Comparative effectiveness of the core components of cardiac rehabilitation on mortality and morbidity: a systematic review and network metaanalysis. J Clin Med 2018;7:514.

5 Francis T, Kabboul N, Rac V, et al. The effect of cardiac rehabilitation on health-related quality of life in patients with coronary artery disease: a meta-analysis. Can J Cardiol 2019;35:352-64.

6 Shields GE, Wells A, Doherty P, et al. Cost-effectiveness of cardiac rehabilitation: a systematic review. Heart 2018;104:1403-10.

7 Toufan M, Afrasiabi A. Benefits of cardiac rehabilitation on lipid profile in patients with coronary artery disease. Pak J Biol Sci 2009;12:1307-13. 
8 Kabir A, Sarrafzadegan N, Amini A, et al. Impact of cardiac rehabilitation on metabolic syndrome in Iranian patients with coronary heart disease: the role of obesity. Rehabil Nurs 2012;37:66-73.

9 Sadeghi M, Garakyaraghi M, Taghavi M, et al. The impacts of cardiac rehabilitation program on exercise capacity, quality of life, and functional status of coronary artery disease patients with left ventricular dysfunction. Rehabil Nurs 2015;40:305-9.

10 Khalife-Zadeh A, Dorri S, Shafiee S. The effect of cardiac rehabilitation on quality of life in patients with acute coronary syndrome. Iran J Nurs Midwifery Res 2015;20:588.

11 Santiago de Araújo Pio C, Beckie TM, Varnfield M, et al. Promoting patient utilization of outpatient cardiac rehabilitation: a joint international Council and Canadian association of cardiovascular prevention and rehabilitation position statement. Int J Cardiol 2020;298:S206-7.

12 Nalini M. Outpatient cardiac rehabilitation use after coronary bypass surgery in the West of Iran. J Cardiopulm Rehabil Prev 2014;34:263-70.

13 Fernandez RS, Salamonson Y, Juergens C, et al. Development and preliminary testing of the cardiac rehabilitation Enrolment obstacles (CREO) scale: implications for service development. Eur J Cardiovasc Nurs 2008;7:96-102.

14 Sarrafzadegan N, Rabiei K, Shirani S, et al. Drop-out predictors in cardiac rehabilitation programmes and the impact of sex differences among coronary heart disease patients in an Iranian sample: a cohort study. Clin Rehabil 2007;21:362-72.

15 Moradi B, Esmaeilzadeh M, Maleki M, et al. Factors associated with failure to complete phase II cardiac rehabilitation: survey registry in Rajaie cardiovascular medical and research center. Int Cardiovasc Res J 2012;5:139-42.

16 Ghanbari-Firoozabadi M, Vafaii Nasab M, Boostani F, et al. Establishment of cardiac rehabilitation program in Yazd-Iran: an experience of a developing country. Int $J$ Cardiol Heart Vasc 2019;24:100406

17 Neubeck L, Freedman SB, Clark AM, et al. Participating in cardiac rehabilitation: a systematic review and meta-synthesis of qualitative data. Eur J Prev Cardiol 2012;19:494-503.

18 Ragupathi L, Stribling J, Yakunina Y, et al. Availability, use, and barriers to cardiac rehabilitation in LMIC. Glob Heart 2017;12:323-34.

19 Shahsavari H, Shahriari M, Alimohammadi N. Motivational factors of adherence to cardiac rehabilitation. Iran J Nurs Midwifery Res 2012;17:318-24.

20 Hamedani B, Shahsavari H, Amaniyan S, et al. Development and psychometric evaluation of the cardiac rehabilitation adherence tool (CrAT). J Cardiovasc Dev Dis 2019;6:25.

21 Ghisi GLdeM, dos Santos RZ, Aranha EE, et al. Perceptions of barriers to cardiac rehabilitation use in Brazil. Vasc Health Risk Manag 2013;9:485-91.

22 Horwood $\mathrm{H}$, Williams MJA, Mandic S. Examining motivations and barriers for attending maintenance community-based cardiac rehabilitation using the health-belief model. Heart Lung Circ 2015;24:980-7.

23 Shanmugasegaram S, Oh P, Reid RD, et al. Cardiac rehabilitation barriers by rurality and socioeconomic status: a cross-sectional study. Int J Equity Health 2013;12:72.

24 Mair V, Breda AP, Nunes MEB, et al. Evaluating compliance to a cardiac rehabilitation program in a private General Hospital. Einstein 2013;11:278-84.

25 Grace SL, Shanmugasegaram S, Gravely-Witte S, et al. Barriers to cardiac rehabilitation: does age make a difference? J Cardiopulm Rehabil Prev 2009;29:183-7.

26 Grace SL, Gravely-Witte S, Kayaniyil S, et al. A multisite examination of sex differences in cardiac rehabilitation barriers by participation status. J Womens Health 2009;18:209-16.

27 Shanmugasegaram S, Oh P, Reid RD, et al. A comparison of barriers to use of home- versus site-based cardiac rehabilitation. $J$ Cardiopulm Rehabil Prev 2013;33:297-302.
28 Shanmugasegaram S, Gagliese L, Oh P, et al. Psychometric validation of the cardiac rehabilitation barriers scale. Clin Rehabil 2012;26:152-64.

29 Grisay A. Translation procedures in OECD/PISA 2000 international assessment. Language Testing 2003;20:225-40.

30 Kyriazos TA. Applied Psychometrics: the 3-Faced construct validation method, a routine for evaluating a factor structure. Psychology 2018;09:2044-72.

31 Bartram D, Berberoglu G, Grégoire J, et al. ITC guidelines for translating and adapting tests (second edition). Int $J$ Test 2018;18:101-34.

32 Consortium. Translation and adaptation guidelines for Pisa 2012. Budapest, 2010. Available: https://www.oecd.org/pisa/pisaproducts/ 49273486.pdf [Accessed 3 Feb 2020].

33 Mokkink LB, Terwee CB, Patrick DL, et al. The COSMIN study reached international consensus on taxonomy, terminology, and definitions of measurement properties for health-related patientreported outcomes. J Clin Epidemiol 2010;63:737-45.

34 Bujang MA, Baharum N. A simplified guide to determination of sample size requirements for estimating the value of intraclass correlation coefficient: a review. Arch Orofac Sci 2017;12:1-11.

35 Marsh HW, Hau K-T, Grayson D. Goodness of fit in structural equation models. In: McDonald RP, ed. Contemporary Psychometrics. USA: Lawrence Erlbaum Associates, 2005: 275-340.

36 Taber KS. The Use of cronbach's alpha when developing and reporting research instruments in science education. Res Sci Educ 2018;48:1273-96.

37 Bakhshayeh S, Sarbaz M, Kimiafar K, et al. Barriers to participation in center-based cardiac rehabilitation programs and patients' attitude toward home-based cardiac rehabilitation programs. Physiother Theory Pract 2019:1-11.

38 Ghisi GLdeM, Santos RZdos, Schveitzer V, et al. Development and validation of the Brazilian Portuguese version of the cardiac rehabilitation barriers scale. Arq Bras Cardiol 2012;98:344-51.

39 Baek S, Park H-W, Lee Y, et al. Translation, cross-cultural adaptation and psychometric validation of the Korean-Language cardiac rehabilitation barriers scale (CRBS-K). Ann Rehabil Med 2017:41:858-67.

40 Sánchez Delgado JC, Jácome Hortúa A, Larios Martínez B, et al. Reliability of the barriers scale for cardiac rehabilitation. Rev Colomb Cardiol 2018;25:84-91.

41 Chai LS, Siop S, Putit Z, et al. Translation, adaptation, and validation of the Malay version of the cardiac rehabilitation barriers scale. J Nurs Res 2020;28:e64.

42 Grace SL, Chessex C, Arthur $\mathrm{H}$, et al. Systematizing inpatient referral to cardiac rehabilitation 2010: Canadian association of cardiac rehabilitation and Canadian cardiovascular Society joint position paper endorsed by the cardiac care network of Ontario. Can J Cardiol 2011;27:192-9.

43 Pio CSdeA, Chaves G, Davies P, et al. Interventions to promote patient utilization of cardiac rehabilitation: cochrane systematic review and meta-analysis. J Clin Med 2019;8:189.

44 Babu AS, Lopez-Jimenez F, Thomas RJ, et al. Advocacy for outpatient cardiac rehabilitation globally. BMC Health Serv Res 2016;16:471.

45 Vahedian-Azimi A, Miller AC, Hajiesmaieli M, et al. Cardiac rehabilitation using the Family-Centered Empowerment model versus home-based cardiac rehabilitation in patients with myocardial infarction: a randomised controlled trial. Open Heart 2016;3:e000349.

46 Saeidi M, Soroush A, Komasi S, et al. A hybrid cardiac rehabilitation is as effective as a hospital-based program in reducing chest pain intensity and discomfort. Korean J Pain 2017;30:265-71.

47 Najafi F, Nalini M. Hospital-based versus hybrid cardiac rehabilitation program in coronary bypass surgery patients in Western Iran: effects on exercise capacity, risk factors, psychological factors, and quality of life. J Cardiopulm Rehabil Prev 2015;35:29-36. 